\title{
ANÁLISE DA UTILIZAÇÃO DA DEMONSTRAÇÃO DO FLUXO DE CAIXA COMO UM INSTRUMENTO DE GESTÃO FINANCEIRA NAS SOCIEDADES ANÔNIMAS DE CAPITAL ABERTO DO ESTADO DO RIO GRANDE DO SUL
}

\author{
Alexandre Costa Quintana' \\ Valter Saurin ${ }^{2}$
}

\begin{abstract}
Resumo
Este trabalho foi elaborado com o objetivo de analisar se efetivamente a Demonstração do Fluxo de Caixa está sendo utilizada como um instrumento de gestão financeira, pelas sociedades anônimas de capital aberto do Estado do Rio Grande do Sul. Em termos metodológicos, elaborou-se um questionário que procurou atender aos objetivos da pesquisa e foi enviado às sociedades anônimas de capital aberto do Estado do Rio Grande do Sul. Além disso, realizou-se uma análise documental nos demonstrativos contábeis e financeiros dessas sociedades. A partir dos dados dos questionários, foi feita uma análise, pela qual se concluiu que a Demonstração do Fluxo de Caixa está sendo utilizada como um instrumento de gestão financeira por um número reduzido de sociedades anônimas de capital aberto do Estado do Rio Grande do Sul. Concluiu-se, ainda, que tal Demonstração tem sido mais usada como um demonstrativo complementar e que, em alguns momentos, ela traz contribuição para a gestão.
\end{abstract}

Palavras-chave: Demonstração do Fluxo de Caixa. Gestão Financeira. Demonstrações Contábeis.

\section{INTRODUÇÃO}

No início da década de 1980, os órgãos internacionais de regulamentação contábil iniciaram estudos para introduzir a Demonstração do Fluxo de Caixa (DFC)

\footnotetext{
' Mestre em Administração pela Universidade Federal de Santa Catarina (UFSC). Professor do Instituto de Ciências Econômicas, Administrativas e Contábeis da Universidade Federal do Rio Grande (FURG). Endereço: Rua Chefe Carlos Araújo, 166, Cassino, Rio Grande, RS, CEP96206-2 I0. E-mail: quintana@vetorial.net.

${ }^{2}$ Doutor em Administração de Empresas pela EASP/FGV. Professor do Departamento de Ciências da Administração da Universidade Federal de Santa Catarina (UFSC). Endereço: Campus da Trindade - CSE CAD SALA 221, CEP: 80090-970, Florianópolis, SC. E-mail: vasaurin@mboxl.ufsc.br. Artigo recebido em: 10/04/2006. Aceito em: 04/03/2008. Membro do Corpo Editorial Científico responsável pelo processo editorial: Gilberto de Oliveira Moritz.
} 
em substituição à Demonstração de Origens e Aplicações de Recursos (DOAR) nos demonstrativos contábeis. O primeiro país a oficializar essa substituição foi o Canadá, em setembro de 1985. Em outros países, a DFC também foi oficializada como, por exemplo, nos Estados Unidos, em novembro de 1987 e no Reino Unido, em 1991. No entanto, na França e na Alemanha existe a recomendação de publicação dos dois demonstrativos (LUSTOSA, 1997).

No Brasil, o Projeto de Lei no 3.741, que tramita na Câmara dos Deputados, determina a substituição citada no parágrafo anterior, pois a DFC vem sendo tratada como um importante instrumento no processo de gestão financeira.

Diante do exposto, o problema de pesquisa foi: “A Demonstração do Fluxo de Caixa está sendo utilizada como um instrumento de gestão financeira pelas sociedades anônimas de capital aberto do Estado do Rio Grande do Sul?"

O objetivo geral deste estudo foi analisar se efetivamente a Demonstração do Fluxo de Caixa está sendo utilizada como um instrumento de gestão financeira pelas sociedades anônimas de capital aberto do Estado do Rio Grande do Sul.

Os objetivos específicos foram:

a) Identificar se as empresas elaboram a Demonstração do Fluxo de Caixa como um instrumento para tomada de decisão interna ou apenas para divulgação externa.

b) Verificar quais os tipos de decisões tomadas pelos administradores das empresas, em função da utilização da Demonstração do Fluxo de Caixa.

c) Verificar se a Demonstração do Fluxo de Caixa é elaborada pelo método direto ou pelo indireto.

d) Verificar se as empresas utilizam medidas de desempenho para analisar sua Demonstração do Fluxo de Caixa.

e) No caso das empresas que não utilizam a Demonstração do Fluxo de Caixa, verificar quais são os instrumentos utilizados na gestão financeira.

Atualmente, a Demonstração do Fluxo de Caixa é utilizada nos Estados Unidos, no Canadá e em vários países como um instrumento importante no processo de administração financeira e contábil das empresas (LUSTOSA, 1997).

No Brasil, as empresas estão percebendo a importância desse instrumento, pois várias delas já incorporaram a Demonstração do Fluxo de Caixa como um demonstrativo contábil a ser anualmente publicado, junto aos relatórios administrativos elaborados pela empresa.

A intenção deste estudo, em termos de acréscimo ao conhecimento existente, é mostrar como as empresas estão utilizando a demonstração do fluxo de caixa na gestão das atividades financeiras, principalmente no sentido de identificar as decisões mais importantes tomadas na área financeira. É importante destacar que este 
trabalho foi elaborado com base nos resultados da pesquisa realizada pelos autores deste artigo, como parte de dissertação de mestrado defendida e aprovada em 07 de dezembro de 2004, no curso de Pós-Graduação em Administração da Universidade Federal de Santa Catarina.

A gestão do fluxo de caixa não se constitui em preocupação exclusiva das grandes empresas, mas das organizações em geral. Porém, para viabilizar o estudo, definiu-se a utilização das sociedades anônimas de capital aberto, porque essas organizações, além de serem obrigadas a publicar as demonstrações, precisam mostrar aos acionistas e futuros compradores de ações como se apresentam suas condições financeiras. Por isso, a Demonstração do Fluxo de Caixa pode ser um importante instrumento de informações para as pessoas ou as empresas.

\section{FUNDAMENTAÇÃO TEÓRICA}

O fluxo de caixa e sua gestão inserem-se no conjunto de ferramentas que o administrador financeiro dispõe para realizar sua função.

\subsection{Administração financeira}

Grande parte dos fatos que ocorrem nas empresas envolve a movimentação de recursos financeiros. Por isso, a administração financeira acaba tornando-se um elemento indispensável no processo administrativo das empresas.

A importância da administração financeira encontra-se, conforme Zdanowick (2000), na responsabilidade pela gerência das operações relativas à formação de recursos financeiros que serão utilizados para o pagamento dos fatores de produção ou de serviços e a distribuição desses recursos, bem como nas obrigações relacionadas às transações comerciais e de crédito da empresa.

$\mathrm{Na}$ empresa, a administração financeira é exercida por uma pessoa ou por um grupo de pessoas que pode ter denominações, tais como: vice-presidente de finanças, diretor ou gerente financeiro e controller. As atividades empresariais desenvolvidas por essas pessoas envolvem a movimentação de recursos; por isso são definidas as funções básicas do administrador financeiro de uma empresa que, conforme Hoji (2000), são: análise, planejamento e controle financeiro; tomada de decisões de investimentos; tomada de decisões de financiamentos.

\subsection{Administração do capital de giro}

O capital de giro tem participação relevante no contexto operacional das empresas, representando uma parcela significativa de seus ativos totais investidos. 
Conceitualmente, Neves e Viceconti (1998, p. 243) dizem que capital de giro "representa o capital circulante (ativo circulante), ou seja, os recursos que possuem constante movimentação no período". Por conseqüência, serve para identificar os recursos próprios e de terceiros, que foram aplicados no ciclo operacional. Nota-se que esse ciclo representa a aplicação de recursos na atividade da entidade até a formação dos estoques que, mediante venda, voltarão a ser valores disponíveis.

Para Assaf Neto e Silva (1997, p. 15), o capital de giro, também tratado como capital circulante, "é representado pelo ativo circulante, isto é, pelas aplicações correntes, identificadas geralmente pelas disponibilidades, valores a receber e estoques". De uma forma mais ampla, todos os recursos demandados por uma empresa para financiar suas necessidades operacionais são considerados capital de giro.

A administração de capital de giro é um dos elementos mais significativos da administração financeira. Segundo Gitman (1987, p. 279), “a administração de capital de giro abrange a administração de contas circulantes da empresa, incluindo ativos circulantes e passivos circulantes". Nesse contexto, o capital de giro precisar manter-se no menor nível necessário para permitir o desempenho do volume atual e previsto da atividade operacional.

Conforme Hoji (2000), as principais fontes de financiamento do capital de giro são onerosas, pois são representadas pelos empréstimos e financiamentos bancários e pelos parcelamentos de impostos vencidos, que normalmente geram valores significativos de encargos financeiros.

Para que as empresas alcancem um equilíbrio em seu capital de giro, é preciso encontrar um equilíbrio financeiro que, conforme o conceito de Assaf Neto e Silva (1997, p. 24), "é verificado quando suas obrigações financeiras se encontram lastreadas em ativos com prazos de conversão em caixa similares aos dos passivos", ou seja, uma vinculação entre liquidez dos ativos e os desembolsos demandados pelos passivos.

\subsection{Administração de disponibilidades}

A administração de disponibilidades é um importante elemento para que o administrador financeiro analise até que ponto a falta de liquidez possa vir a provocar perdas para a empresa, pois está inserido na administração do disponível, conforme Zdanowick (2000, p. 188-189), "o controle da eficiente utilização de recursos da empresa, em investimentos facilmente conversíveis em numerário e das fontes externas que podem proporcionar imediatos aportes de recursos financeiros quando necessários".

O principal componente da administração de disponibilidades é o caixa, e ele é controlado através da utilização do fluxo de caixa que é um eficiente instrumento gerencial, ou seja, conforme Frezatti (1997, p. 28) "é aquele que permite apoiar o processo decisório da organização, de maneira que ela esteja orientada para os resultados pretendidos". 
Nesse sentido, Braga (1989, p. 124) afirma que "as projeções dos fluxos de entradas e de saídas de numerário constituem um instrumento imprescindível na administração de disponibilidades", pois é fundamental conhecer antecipadamente a quantidade de recursos que irá sobrar ou faltar nos próximos dias.

\subsection{Conceituação do fluxo de caixa}

De uma forma conceitual, de acordo com Zdanowicz (2000, p. 40), "denomina-se por fluxo de caixa projetado ao conjunto de ingressos e desembolsos de numerário ao longo de um período projetado", servindo para representação da situação financeira de uma empresa, levando em consideração as fontes de recursos e a forma de aplicação em elementos do ativo.

Para Zdanowicz (2000, p. 125), o fluxo de caixa "é um dos instrumentos mais eficientes de planejamento e controle financeiro", constituindo-se, em conseqüência, em elemento básico e indispensável para o administrador, sendo de grande importância para avaliar a posição financeira da empresa a longo prazo.

É nesse contexto que Assaf Neto e Silva (1997) destacam o fluxo de caixa como um instrumento que possibilita o planejamento e o controle dos recursos financeiros de uma empresa, sendo, a nível gerencial, indispensável em todo o processo de tomada de decisões financeiras.

Para Frezatti (1997), em algumas organizações, o fluxo de caixa serve como um instrumento tático e, em outras, o alcance é maior, ou seja, sua utilização é estratégica. A abordagem tática refere-se a um uso restrito e de acompanhamento do fluxo de caixa, aparecendo como um cumpridor de determinações mais amplas e complexas, em que a empresa já possui um escopo mais definido em termos estratégicos e quer apenas manter o rumo. A abordagem estratégica é aquela que afeta o nível de negócios da empresa no curto prazo e, principalmente no longo prazo, assim o fluxo de caixa tem efeito sobre questões ligadas às decisões realmente estratégicas da empresa.

A importância do fluxo de caixa também está na abrangência de sua interferência, pois não só a área financeira deve estar comprometida com os resultados de caixa, mas também as demais áreas da empresa, conforme destaca Assaf Neto e Silva (1997):

a) a área de produção muda os prazos de fabricação dos produtos e, por conseqüência, promove alterações nas necessidades de caixa; da mesma forma, os custos de produção têm significativos reflexos sobre o caixa;

b) as decisões de compras devem estar em sintonia com a existência de saldos disponíveis de caixa, ou seja, deve haver preocupação com a sincronização dos fluxos de caixa, avaliando-se a relação entre os prazos obtidos para pagamento das compras com os definidos para recebimento das vendas; 
c) políticas de cobrança mais ágeis e eficientes permitem a disponibilização dos recursos financeiros de uma forma mais rápida, resultando em um importante reforço de caixa;

d) a área de vendas deve manter um controle mais próximo sobre os prazos concedidos e sobre os hábitos de pagamentos dos clientes, de maneira a não pressionar negativamente o fluxo de caixa, ou seja, as decisões envolvendo vendas devem ser tomadas somente após uma prévia avaliação de suas implicações sobre os resultados de caixa; e

e) a área financeira deve avaliar cuidadosamente o perfil de seu endividamento, de forma que os desembolsos necessários ocorram concomitantemente à geração de caixa da empresa.

\subsection{Demonstração do fluxo de caixa}

A Demonstração do Fluxo de Caixa (DFC) não é, até o momento, uma demonstração oficial exigida pela Lei $n^{\circ} 6.404 / 76$, mas é um instrumento muito importante para a administração financeira, pois, para Perez Júnior e Begalli (1999, p. 178), essa demonstração "já comprovou ser de extrema utilidade para diversos fins, dada sua simplicidade e abrangência, principalmente no que diz respeito aos aspectos financeiros que envolvem o dia-a-dia da entidade".

O objetivo primário da DFC, segundo Iudícibus, Martins e Gelbcke (2000, p. 351), "é prover informações relevantes sobre os pagamentos e recebimentos, em dinheiro de uma empresa, ocorridos durante um determinado período", facilitando o processo de administração dos recursos disponíveis na empresa.

De uma forma condensada, segundo Marion (1998, p. 380), a DFC “indica a origem de todo o dinheiro que entrou no caixa, bem como a aplicação de todo o dinheiro que saiu do caixa em determinado período", o mesmo autor lembra também que deve apresentar o Resultado do Fluxo Financeiro.

A DFC divide-se em três grupos: fluxos relativos às atividades operacionais, relativos às atividades de financiamento e relativos às atividades de investimento. Assim, segundo Salotti e Yamamoto (2004, p. 7), a DFC torna-se "uma valiosa ferramenta para analisar os efeitos das atividades operacionais, de investimento e de financiamento no fluxo de caixa de um determinado período".

De acordo com Iudícibus, Martins e Gelbcke (2000, p. 352-353), são consideradas atividades operacionais:

Entradas:

a) recebimentos pela venda de produtos e serviços a vista, ou das duplicatas correspondentes no caso de vendas a prazo. Incluem também os recebimentos decorrentes dos descontos das duplicatas emitidas contra 
as vendas a prazo efetuadas, de curto ou longo prazo, em bancos;

b) recebimento de juros sobre empréstimos concedidos e sobre aplicações financeiras em outras atividades;

c) recebimento de dividendos pela participação no patrimônio de outras empresas;

d) qualquer outro recebimento que não se origine de transações definidas como atividades de investimento ou financiamento, como: recebimentos decorrentes de sentenças judiciais; indenizações por sinistros, exceto aquelas diretamente relacionadas a atividades de investimento ou financiamento, como o sinistro em uma edificação, por exemplo; e reembolso de fornecedores.

Saídas:

a) pagamentos a fornecedores referentes ao suprimento da matériaprima para a produção ou de bens para revenda. Se compra a prazo, pagamento do principal dos títulos de curto e longo prazos a que se refere a compra;

b) pagamentos aos fornecedores de outros insumos de produção, incluídos os serviços prestados por terceiros;

c) pagamentos aos governos federal, estadual e municipal, referentes a impostos, multas, alfândega e outros tributos e taxas;

d) pagamento dos juros (despesas financeiras) dos financiamentos (comerciais e bancários) obtidos.

Devem ser consideradas atividades de financiamento, conforme De Santi e Olinquevitch (1993, p. 168-169):

Fundos de caixa despendidos para:

- remuneração aos proprietários na forma de dividendos ou outras distribuições;

- pagamento de valores tomados por empréstimos, inclusive empréstimos de curto e longo prazo, obrigações de leasing de capital e resgate de debêntures;

- reaquisição de ações próprias e outros títulos de emissão própria relativos ao patrimônio líquido;

Fundos de caixa recebidos de :

- emissão de ações;

- subscrição de debêntures, hipotecas e empréstimos de curto e longo prazo;

Com relação às atividades de investimento, são elencadas por Iudícibus, Martins e Gelbcke (2000, p. 353) as seguintes operações:

Entradas:

a) recebimento do principal dos empréstimos concedidos ou da venda desses ativos a outras entidades, exceto ativos financeiros classificados como equivalentes-caixa; 
b) recebimento pela venda de títulos de investimento a outras entidades;

c) recebimento pela venda de participações em outras empresas;

d) recebimento pelo resgate de participações pelas entidades investidas;

e) venda de imobilizado e de outros ativos fixos utilizados na produção. Saídas:

a) desembolso dos empréstimos concedidos pela empresa e pagamento pela aquisição de títulos de investimento de outras entidades;

b) pagamento pela aquisição de títulos patrimoniais de outras empresas;

c) pagamento, no momento da compra ou em data próxima a esta, de terreno, edificações, equipamentos ou outros ativos fixos utilizados na produção.

O órgão mundial normatizador da contabilidade é o International Accounting Standards Board (IASB) que, através da NIC 7 - Norma Internacional de Contabilidade, definiu o objetivo e a forma de utilização da DFC.

De acordo com o IBRACON (1998), nessa norma encontra-se a observação de que o uso da DFC, juntamente com as demais demonstrações contábeis, pode proporcionar informações que habilitam os usuários a avaliar as mudanças ocorridas nos ativos líquidos de uma empresa, na sua estrutura financeira e, ainda, a verificar o reflexo nas importâncias e nos prazos dos fluxos de caixa.

Para Kroetz (2000, p. 39), a DFC “apresenta a modificação no saldo das disponibilidades da entidade durante determinado período, por meio dos fluxos de pagamentos e recebimentos", ressaltando que essa demonstração agrega valores constantes no caixa e nos bancos.

Por isso, nota-se que é importante destacar que, na elaboração da DFC, o conceito de caixa é ampliado para também considerar os investimentos qualificados como equivalentes de caixa. Conforme Iudícibus, Martins e Gelbcke (2000, p. 352), "equivalentes-caixa são investimentos de altíssima liquidez, prontamente conversíveis em uma quantia conhecida de dinheiro e que apresentam risco insignificante de alteração de valor". Deve-se ressaltar que a definição citada é a adotada pelo IASB.

\subsection{Formas de apresentação da Demonstração do Fluxo de Caixa}

A DFC pode ser elaborada, segundo Neves e Viceconti (1998), por meio de duas formas: o método direto e o método indireto.

O método direto, conforme descrito por Iudícibus, Martins e Gelbcke (2000, p. 355), "explicita as entradas e saídas brutas de dinheiro dos principais componentes das atividades operacionais, como recebimentos pelas vendas de produtos e serviços e os pagamentos a fornecedores e empregados", resultando ao final o volume líquido de caixa provido ou consumido pelas operações da empresa.

De acordo com Iudícibus, Martins e Gelbcke (2000, p. 355), "o método indireto faz a conciliação entre o lucro líquido e o caixa gerado pelas operações", 
permitindo que o usuário avalie quanto do lucro está sendo transformado em caixa a cada período.

A diferença efetiva existente entre o método direto e o indireto é a estruturação do fluxo de caixa das atividades operacionais, pois conforme Perez Jr. e Begalli (1999, p. 179), "o método indireto parte do resultado das operações sociais, isto é, o lucro líquido do período, ajustado pelas despesas e receitas que não interferem diretamente no caixa ou disponibilidades da entidade, tais como depreciações, amortizações, exaustões". O método direto demonstra todos os pagamentos e recebimentos relativos à atividade operacional das empresas.

Em conseqüência pode-se afirmar que os fluxos das atividades de investimento e de financiamento são iguais, tanto no método direto, como no indireto, pois, conforme observa Neves e Viceconti (1998), a diferença entre os métodos está apenas na forma de apresentar os recursos derivados das operações.

\subsection{Medidas de desempenho obtidas da Demonstração do Fluxo de Caixa}

A DFC, da mesma forma que as outras demonstrações financeiras, pode ser analisada com base em índices ou indicadores financeiros. Em função disso, Braga e Marques (2001) propõem quatro categorias distintas de indicadores para medir o desempenho da DFC, conforme a seguir: na primeira categoria, os quocientes de cobertura possibilitam a avaliação da liquidez do empreendimento; a segunda categoria mostra os indicadores de qualidade do resultado; a terceira categoria abrange as medidas de dispêndios de capital; e na quarta categoria estão os indicadores de fluxo de caixa por ação e retorno sobre o investimento.

Todas as categorias citadas formam um conjunto de informações que servirão para analisar a previsão de fluxos futuros e a medição de desempenho dos fluxos correntes de caixa, que, junto aos demais quocientes tradicionais, poderão representar um acompanhamento mais detalhado da situação financeira das empresas e, por conseqüência, a obtenção de elementos importantes no processo de gestão financeira.

\subsection{Instrumentos utilizados no processo de gestão financeira}

Além do fluxo de caixa e da DFC, outros instrumentos são utilizados durante o processo de gestão financeira, servindo também para avaliar essa gestão.

A Demonstração do Valor Adicionado (DVA) não é um demonstrativo obrigatório, mas um grupo seleto de empresas está utilizando e divulgando a DVA, conforme Neves e Viceconti (1998, p. 261), "como informação adicional nos relatórios de Administração ou como Nota Explicativa às Demonstrações Financeiras”. 
A DVA vem sendo utilizada como um instrumento de avaliação da gestão financeira, pois, de acordo com Blatt (2001, p. 153), esse demonstrativo "tem como objetivo principal informar o valor da riqueza criado pela empresa e a forma de sua distribuição".

A Demonstração do Resultado do Exercício (DRE) é outro instrumento utilizado para a avaliação da gestão financeira, pois, conforme Assaf Neto (2001, p. 75), esse demonstrativo "visa fornecer, de maneira esquematizada, os resultados (lucro ou prejuízo) auferidos pela empresa em determinado exercício social". Assim, esses resultados mostram como se apresenta a gestão econômica e o reflexo futuro na gestão financeira, servindo de elemento para comparação com outras empresas.

Segundo Iudícibus, Martins e Gelbcke (2000, p. 26), o Balanço Patrimonial "tem por finalidade apresentar a posição financeira e patrimonial da empresa em determinada data", representando, assim, uma posição estática da empresa.

O Balanço Patrimonial está estruturado em dois grandes grupos: o ativo e o passivo. Conforme Perez Jr. e Begalli (1999, p. 62), "o ativo é composto de bens e direitos de propriedade da sociedade, enquanto o passivo é composto de obrigações e do patrimônio líquido".

A análise financeira, de acordo com Blatt (2001, p. 61), "utiliza a informação contida nos demonstrativos financeiros ou contábeis da entidade; as ferramentas primárias para análise financeira são os índices financeiros”. Essa análise dedicase ao cálculo de índices, de forma a avaliar o desempenho, passado e presente, da empresa, seja através da comparação com "padrões do ramo" em que atua, seja pela análise de séries temporais.

O objetivo da análise financeira, segundo Neves e Viceconti (1998), é fornecer dados numéricos de dois ou mais exercícios, de maneira a contribuir ou instrumentar acionistas, administradores, fornecedores, clientes, governo, instituições financeiras e investidores interessados na situação da empresa, ou para tomar decisões.

EBITDA (Earning Before Interest, Taxes, Depreciation/Depletion and Amortization) é uma medida financeira utilizada no mercado que corresponde em português a lucro antes dos juros, impostos (sobre lucros), depreciações/exaustões e amortizações, equivalendo ao conceito restrito de fluxo de caixa operacional da empresa, apurado antes do cálculo do imposto de renda.

O EBITDA, denominado no Brasil como LAJIDA (Lucro Antes dos Juros, Impostos, Depreciação e Amortização), de acordo com Vasconcelos (2002, p. 41),

[...] engloba todos os componentes operacionais e, desta forma, compreende grande parte das receitas auferidas e despesas incorridas, o que destaca a medida em relação ao Lucro Líquido na visualização do desempenho operacional do negócio [...] 
Análise da utilização da demonstração do fluxo de caixa como um instrumento de gestão financeira nas sociedades...

Sendo assim um importante indicador de desempenho financeiro.

\subsection{Tomada de decisão}

No dia-a-dia das empresas, a todo instante, o administrador precisa tomar decisões. Essas decisões podem ser extremamente simples ou bastante complicadas como: decidir qual investimento deve ser feito ou de qual fornecedor deve ser feita determinada compra. Enfim, essas decisões podem afetar poucas pessoas ou podem definir o futuro da empresa.

A tomada de decisão na administração, segundo Megginson, Mosley e Pietri Jr. (1998, p. 194), "pode ser definida como a escolha consciente de um rumo de ação entre várias alternativas possíveis para se chegar a um resultado desejado", ressaltando que essa decisão não é uma reação involuntária ou inconsciente, mas sim a busca pela melhor alternativa para alcançar um bom resultado.

$\mathrm{Na}$ área financeira, a decisão deve ser tomada com muitos cuidados por parte dos executivos financeiros, porque, conforme Securato (1996, p. 11), decidir “é a mais importante função do Administrador e a que envolve a maior relação custobenefício, quando se trata do Administrador Financeiro", pois poderá significar o fracasso ou o sucesso de toda uma Administração.

\subsection{Sociedades anônimas}

A sociedade anônima é uma entidade empresarial intangível, criada por lei, normalmente conhecida por pessoa jurídica e, de acordo com Gitman (1997, p. 7), "tem poderes semelhantes aos de uma pessoa, no sentido de que pode acionar e ser acionada judicialmente, estabelecer contratos e ser parte deles, e adquirir propriedades em seu próprio nome". As sociedades anônimas podem ser diferenciadas como sociedades de capital aberto e de capital fechado. Tal classificação é feita em função da existência ou não de valores mobiliários negociados em bolsa ou no mercado de balcão.

Por isso, Casagrande Neto (1985, p. 22) conclui que, em função da legislação atual, "é considerada companhia aberta toda sociedade anônima que tenha registro na Comissão de Valores Mobiliários (CVM) com conseqüente autorização para negociação de seus valores mobiliários em Bolsa ou balcão".

Já com relação à companhia fechada, Casagrande Neto (1985, p. 22) classificaa como "aquela que obtém recursos de capital mediante subscrição de ações pelos próprios acionistas ou por um grupo restrito de pessoas", sem nenhuma negociação de valores em bolsa ou balcão. 


\section{METODOLOGIA}

No tocante à tipologia, essa pesquisa caracteriza-se pelo tipo descritivo. Conforme Cervo e Bervian (2002, p. 66), a pesquisa descritiva "procura descobrir, com a precisão possível, a freqüência com que um fenômeno ocorre, sua relação e conexão com outros, sua natureza e características". A pesquisa descritiva ocorre mais freqüentemente nas ciências sociais e humanas, tratando de dados e problemas que não constam em registro documental.

Quanto à abordagem do problema, o estudo utilizou uma abordagem quantitativa e qualitativa para análise dos dados dos questionários e para a análise documental. Para Richardson (1989, p. 29), a abordagem quantitativa "caracteriza-se pelo emprego de quantificação tanto nas modalidades de coleta de informações, quanto no tratamento delas por meio de técnicas estatísticas".

A pesquisa qualitativa, conforme Godoy (1995, p. 58), "não procura enumerar e/ ou medir os eventos estudados, nem emprega instrumental estatístico". Assim parte de questões ou focos de interesses amplos vão se definindo no transcorrer do estudo.

O objeto de estudo dessa pesquisa são as sociedades anônimas de capital aberto do estado do Rio Grande do Sul, correspondendo a aproximadamente 60 empresas. O estudo foi viabilizado com os dados dos questionários respondidos pelos responsáveis pela área financeira dessas empresas, e com as informações constantes dos demonstrativos contábeis publicados e registrados junto à Comissão de Valores Imobiliários (CVM).

O elemento de análise aborda a utilização da DFC e seu estudo documental como um instrumento de gestão financeira, por meio de sua utilização para a tomada de decisões financeiras.

A coleta de dados é a etapa inicial do tratamento dos dados. De acordo com Marconi e Lakatos (1982, p. 30), "é tarefa cansativa e toma, quase sempre, mais tempo do que se espera", exigindo paciência, perseverança e esforço pessoal do pesquisador, além do cuidado no registro dos dados.

Os dados primários, considerados neste trabalho, foram os coletados através dos questionários respondidos.

Os dados secundários são os documentos que foram publicados no Diário Oficial e em jornais de circulação das imediações das empresas, bem como por meio do site da Comissão de Valores Mobiliários que, por ser o órgão normatizador e controlador dessas empresas, disponibiliza documentos do tipo demonstrações financeiras, relatórios, notas explicativas e outros.

O instrumento utilizado foi um questionário (estruturado), com perguntas abertas e fechadas para os dados primários, e uma análise documental referente às publicações dos demonstrativos para os dados secundários. 
Análise da utilização da demonstração do fluxo de caixa como um instrumento de gestão financeira nas sociedades...

Segundo Gil (1994, p. 24), o questionário pode ser definido "como a técnica de investigação composta por um número mais ou menos elevado de questões apresentadas por escrito às pessoas", lembrando que o objetivo dessa investigação é conhecer opiniões, sentimentos, interesses, expectativas, etc.

\section{ANÁLISE E INTERPRETAÇÃO DOS RESULTADOS}

No decorrer dos meses de maio, junho e julho de 2004 foram enviados os questionários da pesquisa para todas as Sociedades Anônimas de Capital Aberto do Estado do Rio Grande do Sul que estavam, no início de maio de 2004, com seu registro em fase operacional no cadastro da Comissão de Valores Imobiliários, ou seja, com todos os documentos contábeis e societários atualizados e publicados, podendo realizar todas as ações permitidas para uma Sociedade Anônima de Capital Aberto.

O número total de questionários remetidos foi de 60 , e a forma de envio foi através do correio e por e-mail. Os questionários foram direcionados ao responsável pela área financeira de cada empresa.

\subsection{Características das empresas}

A principal característica exigida nas empresas pesquisadas é a de que todas fossem Sociedades Anônimas de Capital Aberto. Os questionários só foram enviados às empresas que estavam com seus registros junto à $\mathrm{CVM}$, em conformidade com a legislação.

Outra característica observada é a de que, além de possuírem sede jurídica no Estado do Rio Grande do Sul, verificou-se as atividades administrativas e financeiras de cada empresa, se eram controladas nessa sede ou não, afim de traçar efetivamente um perfil das empresas com controle financeiro de suas operações realizado no próprio estado. Assim, foram excluídas da pesquisa as empresas que possuíam sede jurídica no estado do Rio Grande do Sul, mas realizavam o controle financeiro fora.

\subsection{Análise dos questionários}

Do total de questionários remetidos, foram recebidos 48 respostas que representaram o universo da pesquisa, pois correspondem a $80 \%$ do total.

O instrumento de pesquisa era composto por um questionário com 19 questões que respondia às perguntas de pesquisa elaboradas neste trabalho. Nesse caso, as questões foram elaboradas no sentido de verificar qual a utilidade da Demonstração do Fluxo de Caixa no processo de gestão financeira.

A seguir apresenta-se uma síntese das questões mais relevantes, com as respostas e as respectivas análises. 
a) Na empresa, os controles de caixa são subordinados ao:

Tabela 1: Responsável pelo controle de caixa

\begin{tabular}{l|c|c}
\hline \multicolumn{1}{c|}{ FUNÇÃO } & QUANTIDADE & $\%$ \\
\hline Diretor Financeiro & 14 & 29,1 \\
\hline Gerente Financeiro & 24 & 50,0 \\
\hline Controller & 6 & 12,5 \\
\hline Chefe de Contabilidade & 3 & 6,3 \\
\hline Outro: Chefe Depto. Financeiro & 1 & 2,1 \\
\hline TOTAL & 48 & 100,0 \\
\hline
\end{tabular}

Fonte: dados da pesquisa

A Tabela 1 indicou que o controle de caixa fica normalmente subordinado ao gerente financeiro, com 50\%, ou ao diretor financeiro, com 29\%; também foram indicados o controller e os chefes de contabilidade e do departamento financeiro, conforme descrito na Tabela.

b) A empresa elabora a Demonstração do Fluxo de Caixa? (como demonstrativo contábil)

Tabela 2: Empresas que elaboram a Demonstração do Fluxo de Caixa

\begin{tabular}{l|c|c}
\hline \multicolumn{1}{c|}{ FUNÇÃO } & QUANTIDADE & $\%$ \\
\hline Sim & 25 & 52 \\
\hline Não & 23 & 48 \\
\hline TOTAL & 48 & 100 \\
\hline
\end{tabular}

Fonte:dados da pesquisa

A Tabela 2 mostra que 52\% das empresas pesquisadas elaboram a Demonstração do Fluxo de Caixa. Em virtude da proposta do Projeto de Lei ${ }^{\circ} 3.741$, que está tramitando no Congresso Nacional e que obriga a elaboração desse demonstrativo, haverá a necessidade de adequação das empresas que ainda não o elaboram, enquanto as que já usam esse demonstrativo, apenas terão que adaptar-se ao possível modelo que será proposto, já que no Brasil não existe um modelo oficial de DFC.

c) A empresa publica, em jornal, a Demonstração do Fluxo de Caixa, junto às demais demonstrações financeiras (contábeis)?

O percentual de empresas que publicam a DFC representa $40 \%$ das empresas que elaboram esse demonstrativo. Considerando que o total de empresas que responderam ao questionário foi de 48 , a quantidade que a publica torna-se, em relação percentual, menos significativa. Foram dez empresas que responderam que a publicam, representando aproximadamente $21 \%$ do universo pesquisado. E, ainda, considerando que as empresas pesquisadas são sociedades anônimas de capital 
aberto, que precisam ser amplas em seus demonstrativos, pois assim mostrarão se é ou não interessante ser acionista de tais empresas, a não elaboração da DFC representa uma perda em termos de informação.

Além disso, nota-se que $60 \%$ das empresas que elaboram a DFC, não a publicam, ou seja, 15 empresas utilizam esse demonstrativo como um documento interno.

d) A Demonstração do Fluxo de Caixa é elaborada por qual método?

Nessa questão ficou identificado que $56 \%$ das empresas que elaboram a DFC utilizam o método indireto, enquanto que as demais utilizam o direto, ou seja, $44 \%$. É importante lembrar que o método direto detalha as atividades operacionais através da descrição de todos os pagamentos e recebimentos, enquanto que o método indireto é estruturado em função do ajuste do lucro líquido do exercício para reconciliá-lo ao fluxo de caixa líquido das atividades operacionais.

Nessa questão, outra informação importante obtida é a de que as empresas que publicam a DFC utilizam o método indireto porque $100 \%$ o usam; mas no que se refere às empresas que o elaboram e não o publicam, a situação se inverte; ou seja, a maioria das empresas utiliza o método direto, pois 11 empresas entre as 15 que não publicam a DFC, usam esse método e apenas quatro usam o método indireto.

\section{Caixa?}

e) A empresa aplica índices de desempenho na Demonstração do Fluxo de

Essa questão foi direcionada apenas para as empresas que elaboram a DFC, ou seja, 25 empresas, correspondendo a $52 \%$ do total pesquisado. Dessa forma, verificouse que poucos são os índices de desempenho aplicados na DFC, não existindo um padrão comum.

f) Na tomada de decisões na área financeira, a empresa utiliza?

Tabela 3: Instrumento utilizado na tomada de decisão na área financeira

\begin{tabular}{l|c|c}
\hline \multicolumn{1}{c|}{ INSTRUMENTO } & QUANTIDADE & $\%$ \\
\hline Fluxo de caixa diário & 38 & 79,2 \\
\hline Demonstração do fluxo de caixa & 01 & 2,1 \\
\hline Os dois instrumentos & 09 & 18,7 \\
\hline TOTAL & 48 & 100,0 \\
\hline
\end{tabular}

Fonte: dados da pesquisa

A Tabela 3 evidencia que o principal instrumento utilizado na tomada de decisões na área financeira é o fluxo de caixa diário, pois 79,2\% das empresas que responderam ao questionário optaram por tal instrumento.

Essa Questão também serviu para identificar que, mesmo as empresas que elaboram a DFC, acabam por utilizar o fluxo de caixa como instrumento de tomada de decisões, pois apenas uma empresa utiliza a DFC como único instrumento e nove empresas usam a DFC e o fluxo de caixa diário. 
g) Para definir a capacidade de investimentos da empresa, quais são os instrumentos financeiros utilizados?

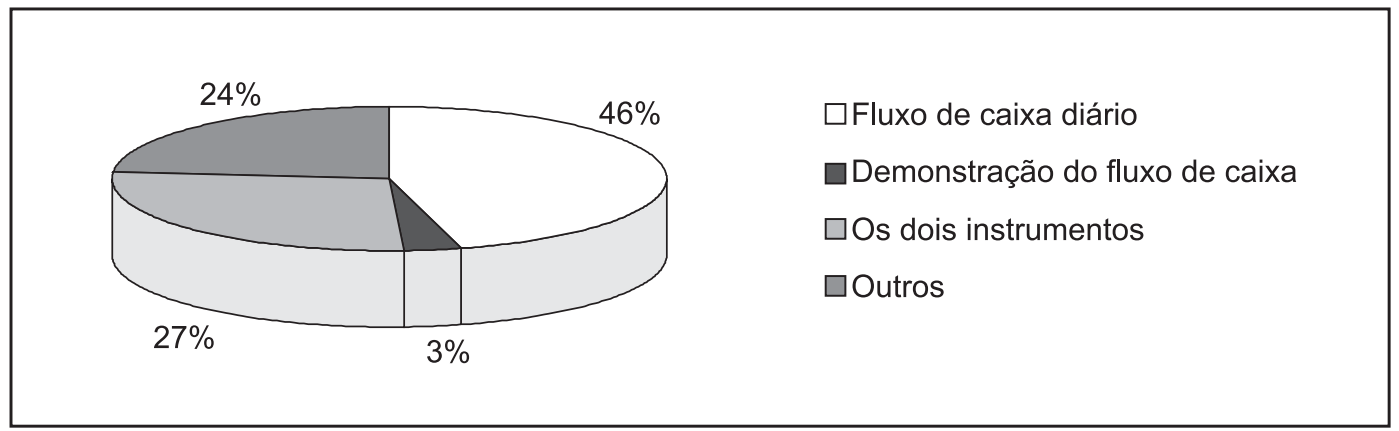

Gráfico 1: Instrumento utilizado para definir a capacidade de investimentos da empresa

Fonte: dados da pesquisa

Os investimentos representam a aplicação de recursos para manutenção das atividades operacionais e com fins estratégicos. Considerando que uma das informações possíveis de ser obtida na Demonstração do Fluxo de Caixa seja a atividade de investimento da empresa, assim, a questão que está representada pelo Gráfico 1, questionava qual o instrumento utilizado para definir a capacidade de investimentos da empresa. O resultado demonstra que o fluxo de caixa diário é o principal instrumento, com $46 \%$, mas a DFC é utilizada em conjunto com o fluxo de caixa em $27 \%$ das respostas. Novamente verifica-se que a DFC existe mais como um dado complementar do que efetivamente como um instrumento na definição da capacidade de investimentos da empresa.

h) Para verificar se a empresa necessitará de recursos, através da obtenção de financiamento, quais são os instrumentos financeiros utilizados?

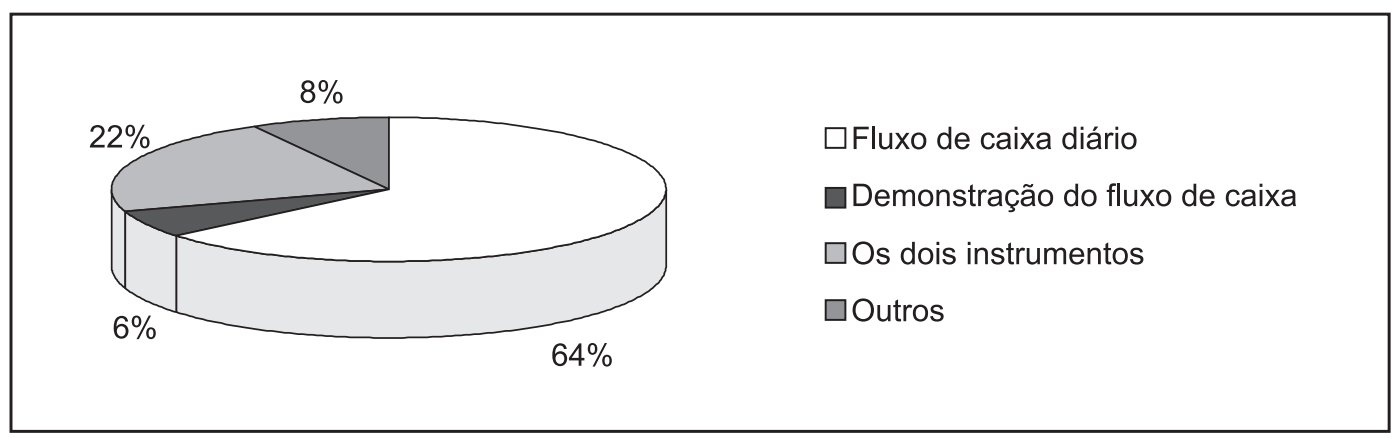

Gráfico 2: Instrumento utilizado para verificar se a empresa necessitará de recursos, através da obtenção de financiamento Fonte: dados da pesquisa 
Da mesma forma que nas demais questões, o instrumento identificado como principal verificador de a empresa necessitar de recursos foi o Fluxo de Caixa diário, com 64\%. Percebe-se que, entre as empresas que elaboram a DFC, a maioria utiliza esse instrumento para definir a obtenção de financiamentos, pois entre as 25 empresas que elaboram a DFC, 14 delas apontaram o método como um instrumento auxiliar na verificação da necessidade de recursos, mesmo que em conjunto com o fluxo de caixa diário.

i) Para projetar a capacidade de honrar seus compromissos com terceiros, quais são os instrumentos financeiros utilizados?

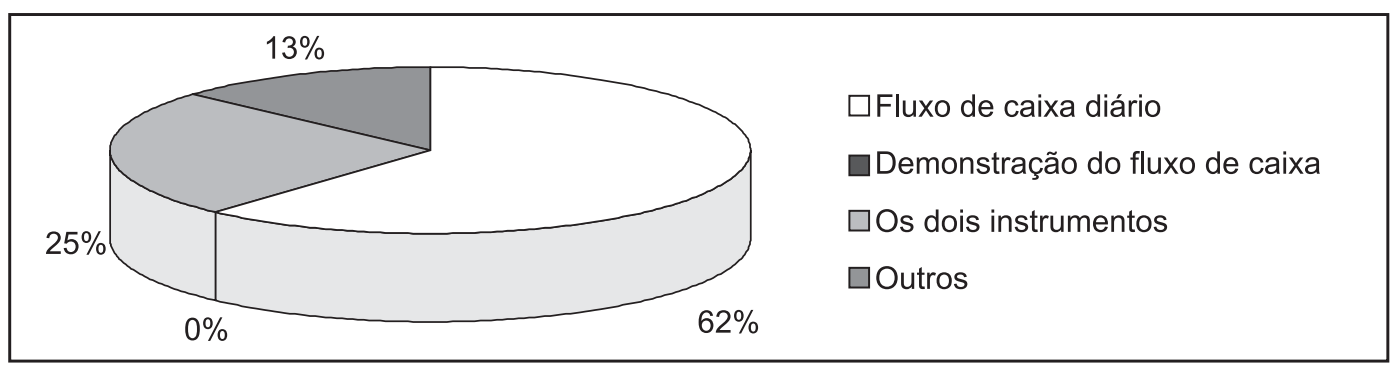

Gráfico 3: Instrumento utilizado para projetar a capacidade de honrar seus compromissos com terceiros

Fonte: dados da pesquisa

Nessa questão, percebe-se que a utilização do fluxo de caixa diário é mais expressiva, pois $62 \%$ das empresas responderam que utilizam apenas esse instrumento para verificar a capacidade de honrar seus compromissos com terceiros e que outros $25 \%$ o utilizam em conjunto com a DFC, ou seja, $87 \%$ das empresas pesquisadas usam o fluxo de caixa diário. De outro lado, nessa questão, a DFC teve os menores percentuais de respostas, pois nenhuma empresa apontou a utilização exclusiva da DFC, e 25\% apontaram a utilização junto a outros instrumentos.

j) Normalmente a projeção de fluxo de caixa é feita para um prazo de:

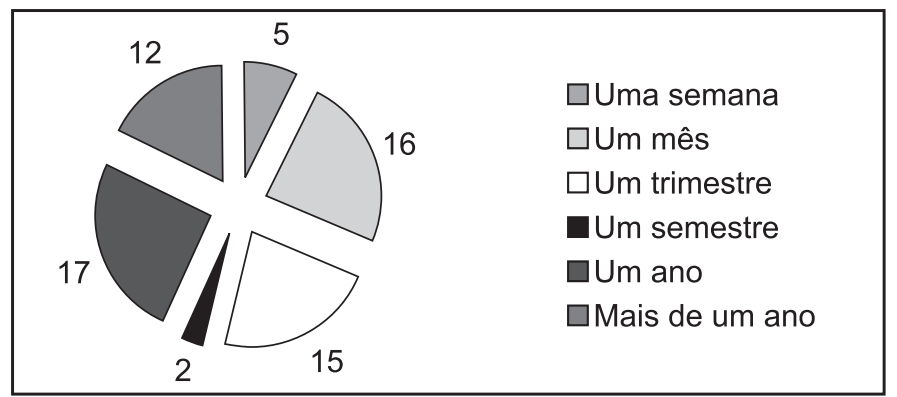

Gráfico 4: Prazo de projeção do fluxo de caixa

Fonte: dados da pesquisa 
Neste trabalho ficou identificado que a projeção de fluxo de caixa é uma atividade presente em todas as empresas pesquisadas, por meio da análise do fluxo de caixa diário, da DFC ou da projeção orçamentária. Essas projeções são feitas em espaços de tempo diferenciados, algumas empresas fazem projeções para um único período e outras fazem para períodos diferenciados. Por meio dessa questão, obteve-se a informação de que o período mais utilizado é o anual, com 17 respostas, seguido do mensal, com 16, e do trimestral, com 15; mas as empresas fazem projeções também para períodos semanais, semestrais e até para mais de um ano, conforme dados do Gráfico 4.

\section{l) O modelo de Demonstração do Fluxo de Caixa elaborado pela empresa é baseado: \\ Com relação aos modelos de DFC utilizados pelas empresas, observou-se que} $32 \%$ das empresas elaboram modelos baseados em normas internacionais ou em função do modelo FASB (Financial Accounting Standards Board), e 52\% elaboram modelos próprios. Essa situação deve-se ao fato de que, no Brasil, não existe um modelo oficial de DFC, em função de que tal demonstração não é obrigatória. Por isso seria importante que o Conselho Federal de Contabilidade, responsável pela regulamentação contábil no Brasil, definisse um modelo desse demonstrativo, pois, como visto nas questões iniciais, $52 \%$ das empresas pesquisadas elaboram a DFC e parte delas a publicam como um demonstrativo contábil. Não existe, porém, um modelo oficial dessa demonstração. Assim, as empresas acabam confeccionando modelos próprios que podem não aproveitar o potencial informativa da DFC.

m) Na opinião do responsável pela área financeira da empresa, a Demonstração do Fluxo de Caixa deve passar a ser elaborada e publicada como um demonstrativo contábil de forma obrigatória pelas empresas?

Essa questão foi elaborada no sentido de verificar se as empresas consideravam importante a obrigatoriedade na elaboração e publicação da DFC, obtendo 52\% de respostas positivas. Também foi solicitada uma justificativa à resposta, pois as respostas também serviram para verificar qual o entendimento e qual a importância dada pelas empresas a esse demonstrativo, pois vários foram os motivos apontados para tornar a DFC obrigatória e vários foram os argumentos contrários à obrigatoriedade, conforme será descrito a seguir.

Entre as respostas a favor da obrigatoriedade na elaboração e publicação da DFC, houve muitas ressaltando a utilidade do demonstrativo como instrumento de transparência da empresa e, por conseqüência, como ferramenta para análise por parte do público externo. Outro ponto favorável à elaboração e à publicação da $\mathrm{DFC}$, refere-se à facilidade de entendimento. Também foi citada a questão da projeção futura da empresa.

Por outro lado, as empresas que responderam não, em um percentual de $48 \%$, também descreveram os seus motivos. $\mathrm{O}$ item mais citado refere-se ao fato de as informações relativas ao caixa serem de interesse exclusivo dos departamentos internos 
da empresa. Outra resposta é a de que os demais demonstrativos já apresentam as informações fornecidas pela DFC, sendo assim desnecessária a sua elaboração.

n) Cargo do funcionário que respondeu este questionário é:

Essa questão foi elaborada no sentido de verificar se a pessoa que respondeu ao questionário estava efetivamente relacionada com o controle do fluxo de caixa. Assim, constatou-se que $83 \%$ das pessoas que responderam exercem cargos de direção ou chefia na área financeira ou contábil, tendo conhecimento para considerar as respostas adequadas. Além disso, dos 17\% que não pertencem a essas áreas, mais da metade exerce função de gerência, sendo constituída por profissionais que precisam ter conhecimento da situação administrativa e financeira da empresa.

\subsection{Análise dos documentos}

A análise documental teve como objetivo verificar como se apresentavam as informações financeiras das empresas pesquisadas, em suas demonstrações contábeis e financeiras publicadas. Para isso foi realizada uma pesquisa junto aos dados constantes no site da Comissão de Valores Mobiliários, que reproduz todas as informações publicadas pelas Sociedades Anônimas de Capital Aberto, visto que são informações públicas e, por isso, disponíveis para consulta.

Por meio da análise de documentos das empresas, verificou-se que, além do fluxo de caixa e da DFC, as empresas utilizam outros instrumentos para descrever a sua situação financeira.

As informações que foram percebidas com mais constância foram: detalhamento dos lucros auferidos na Demonstração do Resultado do Exercício, comparativo do resultado do parâmetro EBITDA, informações relativas aos totais do ativo, passivo e patrimônio líquido do Balanço Patrimonial, elaboração da Demonstração do Valor Adicionado e descrição de índices de análise financeira.

A informação relativa aos lucros auferidos na Demonstração do Resultado do Exercício é utilizada como parâmetro para identificar a situação financeira da empresa. O detalhamento dos lucros é destacado, normalmente, no relatório de administração (documento constante da publicação dos demonstrativos financeiros), com informações sobre o resultado líquido do exercício, o resultado operacional e o resultado bruto, bem como sobre a receita bruta e a receita líquida.

O EBITDA, ou lucro antes dos juros, dos impostos (sobre lucros), das depreciações/exaustões e amortizações é demonstrado também no relatório de administração. Nota-se que esse parâmetro é utilizado para traçar comparativos de um período para o outro, e para compará-lo com valores de empresas do setor.

A Demonstração do Valor Adicionado também é um instrumento utilizado como demonstrativo complementar às informações contábeis e financeiras. Pode-se verificar 
que esse demonstrativo aparece como uma informação financeira, através do valor adicionado ao negócio e como uma informação social, através do detalhamento da distribuição desse valor adicionado.

O Balanço Patrimonial é citado pelas empresas, principalmente para identificar os totais do ativo, do passivo financeiro e do patrimônio líquido, pois dessa forma pode-se ter uma visão do total de recursos que compõem a estrutura patrimonial da empresa.

Outro instrumento utilizado para demonstrar a situação da empresa é a análise financeira por meio de índices. Apesar desse tipo de análise ser normalmente interna, constata-se que várias empresas descrevem os seus índices no relatório de administração. Os índices que foram informados nos documentos pesquisados são: margem bruta, margem operacional, margem líquida, retorno sobre o patrimônio líquido, liquidez corrente, liquidez geral, grau de endividamento de longo prazo e lucratividade.

Além do exposto até aqui, a análise documental serviu para verificar se as informações relativas à elaboração e à publicação da DFC, que constavam nos questionários respondidos, eram confirmadas nos demonstrativos publicados.

Percebe-se efetivamente que entre as 48 empresas que responderam aos questionários, apenas dez o publicam, conforme já apontado na análise dos questionários, realmente todas as empresas que o publicaram utilizaram o método indireto.

$\mathrm{Na}$ análise dos documentos, também foi verificado que as 12 empresas que não responderam ao questionário não publicam a DFC. Esse dado é importante, pois apesar dessas empresas não terem fornecido os dados para pesquisa, foi possível identificar que, do total de sociedades anônimas de capital aberto do estado do Rio Grande do Sul, que estavam com seu registro na CVM em fase operacional, apenas dez publicam a DFC. Considerando o universo de 60 empresas, isso representa que $16,7 \%$ efetivamente publicam a DFC.

\section{CONCLUSÃO}

Este trabalho teve com objetivo geral analisar se efetivamente a Demonstração do Fluxo de Caixa está sendo utilizada como um instrumento de gestão financeira pelas sociedades anônimas de capital aberto do Estado do Rio Grande do Sul.

Pode-se concluir que 52\% das empresas pesquisadas elaboram a DFC, mas a utilizam como um instrumento "auxiliar" na tomada de decisões internas na área financeira. Identificou-se, também, que uma parte das empresas pesquisadas, correspondente a $21 \%$ do total, publicam o demonstrativo com a intenção de divulgação externa, mesmo não sendo um demonstrativo obrigatório.

Após identificar-se que a DFC é utilizada como um instrumento "auxiliar" na tomada de decisão, o próximo momento foi verificar quais os tipos de decisões 
tomadas pelos administradores das empresas, em função da utilização da Demonstração de Fluxo de Caixa. Foi constatado que a DFC pode contribuir para definição da capacidade de investimentos da empresa, para verificar se a empresa necessitará de recursos, através da obtenção de financiamento e para projetar a capacidade de honrar seus compromissos com terceiros, ou seja, efetivamente contribuindo para a tomada de decisões internas na área financeira, mas normalmente sendo utilizada como instrumento "auxiliar" nessas decisões.

Outro ponto constante da fundamentação teórica do trabalho foi identificar qual o método de elaboração da DFC. Ficou constatado que as empresas que publicam a DFC utilizam o método indireto, enquanto as que a elaboram para uso interno, preferem o método direto. De qualquer forma, essa informação mostra que, no Brasil, o método indireto é o mais usado nas publicações.

Considerando que parte das empresas pesquisadas elaboram e publicam a DFC, também foi objetivo deste trabalho verificar se eram utilizadas medidas de desempenho para analisar a DFC, mas constatou-se que essas medidas não são aplicadas sobre o demonstrativo, pois apenas cinco empresas descreveram algum índice utilizado na análise financeira e nenhum desses índices eram específicos da DFC, sendo apenas índices de análise de desempenho financeiro, os quais são obtidos por meio de outros demonstrativos com utilização parcial da DFC.

Com os dados deste trabalho, pode-se afirmar que, no processo de gestão financeira, as empresas utilizam diversos instrumentos, como planos de investimentos, orçamento, projeção de demonstrativos, EBITDA, demonstrações contábeis e outros, mas que o principal instrumento de gestão financeira usado é o fluxo de caixa diário, sendo a DFC utilizada como um documento auxiliar. Essa conclusão responde ao último objetivo específico deste trabalho, que era de verificar, no caso das empresas que não utilizam a Demonstração do Fluxo de Caixa, quais são os instrumentos utilizados na gestão financeira.

Por fim, conclui-se que a DFC está sendo utilizada como um instrumento de Gestão Financeira, por um número reduzido de sociedades anônimas de capital aberto do Estado do Rio Grande do Sul. Isso tem sido usado mais como um demonstrativo complementar e, em alguns momentos, traz contribuição para a gestão, respondendo assim ao objetivo geral deste trabalho que era analisar se efetivamente a Demonstração de Fluxo de Caixa está sendo utilizada como um instrumento de gestão financeira pelas sociedades anônimas de capital aberto do Estado do Rio Grande do Sul.

Ainda é oportuno salientar que as limitações do trabalho detêm-se na população pesquisada, pois as conclusões foram baseadas em informações de um grupo específico de empresas, ou seja, sociedades anônimas de capital aberto do Estado do Rio Grande do Sul. Assim não se pode afirmar que esse seja o resultado de todos os tipos de empresas do país. Por isso, como recomendação para futuros trabalhos, 
apresenta-se a possibilidade de aplicação da pesquisa em outras regiões do país com a finalidade de obter uma visão da utilização da DFC em todo o país. Além disso, seria importante verificar como as empresas que não se classificam como sociedades anônimas de capital aberto tratam a DFC. Na pesquisa, também foi constatado que, além da DFC, existem outros instrumentos importantes na gestão financeira. Por isso é recomendável a realização de estudos desses instrumentos, principalmente no que se refere ao EBITDA, pois é um instrumento muito utilizado pelas empresas, mas com poucos artigos e pesquisas realizados sobre o assunto.

\title{
ANALYSIS OF THE USE OF CASH FLOW STATEMENT AS A TOOL FOR FINANCIAL MANAGEMENT IN OPEN CAPITAL CORPORATIONS IN THE STATE OF RIO GRANDE DO SUL
}

\begin{abstract}
The purpose of this work is to verify whether Cash Flow Statement has really been employed as a tool for financial management by open capital corporations in the State of Rio Grande do Sul, Brazil. In procedural terms, in order to accomplish the purpose of this research a questionnaire was created and sent to open capital corporations in the State of Rio Grande do Sul. Also a documental analysis of accounting and financial statements of those corporations was conducted. The analysis of questionnaire answers shows that the Cash Flow Statement has only been employed as a tool for financial management by a small number of open capital corporations in the State of Rio Grande do Sul, and that this Statement has mainly been employed as a complementary statement, which sometimes provides some contribution for the management.
\end{abstract}

Keywords: Cash Flow Statement. Managerial Financing. Accounting Statement.

\section{REFERÊNCIAS}

ASSAF NETO, Alexandre; SILVA, César Augusto Tibúrcio. Administração do capital de giro. 2. ed. São Paulo: Atlas, 1997.

Estrutura e análise de balanços: um enfoque econômico-financeiro. 6. ed. São Paulo: Atlas, 2001. 
Análise da utilização da demonstração do fluxo de caixa como um instrumento de gestão financeira nas sociedades...

BLATT, Adriano. Análise de Balanços: Estruturação e Avaliação das Demonstrações Financeiras e Contábeis. São Paulo: MAKRON Books, 2001.

BODIE, Zvi; MERTON, Robert C. Finanças. Trad. James Sudelland Cook. Porto Alegre: Artes Médicas Sul, 1999.

BRAGA, Roberto; MARQUES, José Augusto Veiga da Costa. Avaliação da liquidez das empresas através da análise da demonstração de fluxos de caixa. Revista Contabilidade \& Finanças - FIPECAFI - FEA - USP, São Paulo. FIPECAFI. v. 14, n. 25. p. 6-23, janeiro/abril 2001.

BRASIL. Lei n. ${ }^{\mathbf{6}} \mathbf{6 . 4 0 4}$, de 15 de dezembro de 1976. Dispõe sobre as sociedades por ações.

Projeto de Lei $\mathbf{n}^{\mathbf{0}}$ 3741/2000. Altera e revoga dispositivos da Lei ${ }^{0} 6404$, de 15 de dezembro de 1976. Disponível em: <https://www.planalto.gov.br/ccivil_03/ Quadros/Quadro_PL/2000.htm>. Acesso em: 18 set. 2003.

CASAGRANDE NETO, Humberto. Abertura do capital das empresas brasileiras: um enfoque prático. São Paulo: Atlas, 1985.

CERVO, Amado Luiz; BERVIAN, Pedro Alcino. Metodologia Científica. São Paulo: Prentice Hall, 2002.

DE SANTI, Armando; OLINQUEVITCH, José Leônidas. Análise de balanço para controle gerencial. São Paulo: Atlas, 1993.

FREZATTI, Fábio. Gestão do fluxo de caixa diário. São Paulo: Atlas, 1997.

GIL, Antônio Carlos. Métodos e técnicas de pesquisa social. 4. ed. São Paulo: Atlas, 1994.

GITMAN, Lawrence J. Princípios de administração financeira. 7. ed. São Paulo: Harbra, 1997.

GODOY, Arilda Schmidt. Introdução à pesquisa qualitativa e sua possibilidades uma revisão histórica dos principais autores e obras que refletem esta metodologia de pesquisa em Ciências Sociais. Revista de Administração de Empresas, São Paulo, v. 35, n. 2, p. 57-63, março/abril 1995. 
HOJI, Masakazu. Administração Financeira: uma abordagem prática. 2. ed. São Paulo: Atlas, 2000.

IBRACON - Instituto Brasileiro de Contadores. Normas internacionais de contabilidade. São Paulo: IBRACON/CFC, 1998.

IUDÍCIBUS, Sérgio de; MARTINS, Eliseu; GELBCKE, Ernesto Rubens. Manual de contabilidade das sociedades por ações: aplicável também às demais sociedades. 5. ed. São Paulo: Atlas, 2000.

KROETZ, Cesar Eduardo Stevens. Balanço social: teoria e prática. São Paulo: Atlas, 2000.

LAKATOS, Eva Maria; MARCONI, Marina de Andrade. Técnicas de pesquisa: planejamento e execução de pesquisas, amostragens e técnicas de pesquisa, elaboração, análise e interpretação de dados. São Paulo: Atlas, 1982.

LUSTOSA, Paulo Roberto Barbosa. DOAR: uma morte anunciada. Caderno de Estudos - FIPECAFI - FEA - USP, São Paulo. FIPECAFI. v. 9, n. 16, p.26-38, julho/dezembro 1997.

MEGGINSON, Leon C.; MOSLEY, Donald C.; PIETRI JÚNIOR, Paul H. Administração: conceitos e aplicações. Tradução: Maria Isabel Hopp. 4. ed. São Paulo: Harbra, 1998.

NEVES, Silvério das; VICECONTI, Paulo Eduardo V. Contabilidade Avançada: e análise das demonstrações financeiras. 7. ed. ampl., rev. e atual. São Paulo: Frase 1998.

PEREZ JÚNIOR, José Hernandez; BEGALLI, Glaucos Antônio. Elaboração das Demonstrações Contábeis. 2. ed. São Paulo: Atlas, 1999.

RICHARDSON, Roberto Jarry et al. Pesquisa Social: métodos e técnicas. São Paulo: Atlas, 1989.

SALOTTI, Bruno Meirelles; YAMAMOTO, Marina Mitiyo. A estimativa do fluxo de caixa das operações representa o real fluxo de caixa das operações? Revista Contabilidade \& Finanças - USP. São Paulo, n. 35, p. 7-21, maio/agosto 2004. 
Análise da utilização da demonstração do fluxo de caixa como um instrumento de gestão financeira nas sociedades...

SECURATO, José Roberto. Decisões financeiras em condições de risco. São Paulo: Atlas, 1996.

VASCONCELOS, Yumara Lúcia. EBITDA como instrumento de avaliação de empresas. Revista Brasileira de Contabilidade. Brasília, n. 136, p. 38-47, jul./ ago.2002.

ZDANOWICZ, José Eduardo. Fluxo de caixa: uma decisão de planejamento e controle financeiros. 8. ed. Porto Alegre: Sagra-DC Luzzatto, 2000. 